\title{
Excessive Convergence and M\&A Integration of Chinese Regional Cloud Computing Industry
}

\author{
Jing $\mathrm{Hu}^{1}$ and Lili Zhang ${ }^{2}$ \\ ${ }^{1}$ Computer and information engineering institute of Harbin University of Commerce \\ ${ }^{2}$ Basic science institute of Harbin University of Commerce \\ Harbin, 150028, China \\ hujingl@sina.com, Zhangyanyan610@126.com
}

\begin{abstract}
Nowadays, with the rapid development of Chinese cloud computing, there exist problems of regional excessive convergence and overheated investment, namely starting new items blindly, repeating construction and valuing hardware and despising software. The causes of the problems are "three lacks": lacking full demonstration; lacking risk awareness; lacking coordination and cooperation. The important ways of solving the problems are regional cooperation, resource integration and $M \& A$ integration. In practice, business process integration and organization structure integration should be done well. Future Strategy: to strengthen strategic research, top level design and have a better distribution of the country and region; to enhance the cooperation of cloud computing and build sharing platform of network resources; to develop pilot demonstration of application and drive the cultivation and development of applying industry; to quick the standardization of cloud computing and improve healthy development of the industry; to develop leading enterprises and create industrial chain; to cultivate the demand of the market and promote sound progress of industry; to strengthen the regulation of the industry, environmental construction and regulate the behavior of the market.
\end{abstract}

Keywords: Cloud Computing; Excessive Convergence; M\&A Integration

\section{Introduction}

It's important to develop strategic new industry. Cloud computing is an important industrial field of information industry in Chinese strategic new industry. Nowadays, with the rapid development of Chinese cloud computing, there exist problems of regional excessive convergence, overheated investment and repeating construction, which need take relative countermeasures of resource integration and M\&A integration.

\section{The Development and Tendency of World's Cloud Computing}

\subsection{The Development and Tendency of World's Cloud Computing}

Nowadays, cloud computing has become one of the most vigorous fields in ICT (information communication technology). According to the estimate of Gartner, the scale of cloud computing market around the globe has reached 107.2 billion yuan, increasing by $25.3 \%$ annually since 2012 [1]. The development of cloud computing around the globe is very imbalanced. The U.S takes the absolute dominance; the service of international leading enterprises and the innovation of commercial mode are accelerated; the technical penetration 
and integration schemes in the area of private cloud and public cloud are accelerated; the competition of public service cloud is intensified and the price is dropped continuously; the radiation effect of cloud computing industry is begun to show [2]. The governments of each country support the development of the field of big data that is closely related to cloud computing. The U.S. officially launched the plan of research and development in 2012, and Japan restarted the strategic plan of ICT, for big data brought high efficiency. According to the prediction of the research, it's possible for Europe to increase its operating profits to over $60 \%$ by making the full use of distributors of big data; after the government work efficiency is improved by way of using big data, it's estimated that the economy can save expenses over 100 billion European dollars [3]. Meanwhile, big data may lead to the reform of research paradigms [4].

\subsection{The Summary of Current Situation in the Field of Foreign Cloud Computing Research}

Walarop, M. Mitche [5], an American scholar, thinks cloud computing is the data center in the box. Wall dp,Kudtakar P did a research about the issues of cloud computing and biological technology [6]. Zhag yy, Gua LT introduced the information technology and educational issues of 2010 [7]. Wan Ho, Zhao DM, Kong J analyzed the issues of cloud computing and shared technology of library information [8]. Zhou PL and some people of the U.S. researched the issues of cloud computing environment [9]. Yiw, Blake MB researched the issues of cloud computing in the face of service [10]. Wujy and some people researched the platform of cloud computing [11]. Francis and some people researched the core thinking issues of cloud computing security [12]. All of these foreign research results are worth learning for our research.

\section{Excessive Convergence and Causes of Regional Cloud Computing in our Country}

With the guidance of a series of plans, relevant policies and measures, the strong support of all circles in the society and the joint efforts of related people, the cultivation and the development of cloud computing industry in our country show a new aura and situation. Its key performances: (1) R\&D of relevant technology and transformation of relevant scientific and technological results have made progress continuously and had new breakthrough. (2) In some significant industries, the results of R\&D technology have been applied, and many significant platform projects are under construction. (3) The cloud computing centers are being established in some significant regions, and cloud computing basement is being formed. (4) The cloud computing industrial clusters are accelerated, and industry accumulative effect is begun to appear. The industrial upstream and downstream are united, and the industrial chains are formed gradually. (5) Some multinational companies, such as Microsoft, IBM, Goggle, Amazon, etc., have had an active layout of cloud computing in our country.

Some media report that cloud computing in our country has been prosperous recently, and had a good momentum of development. At present, the cloud computing in our country is over focused, which causes blind investment and excess capacity. Among 31 provinces of our country, 28 provinces focus the Internet of Things as a new industry. Some experts think the construction of cloud computing is overheated, so the government should have overall plans [13].

The development of cloud computing industry in our country still faces many challenges and some problems. 
(1) Starting new items blindly. Judging from each region and the construction of cloud computing, there exit issues of planning and starting new items blindly. According to research reports, relevant experts point out that cloud computing in our country appears a new boom. Many local governments construct projects of cloud computing industry actively, however, they lack professional knowledge, deep understanding as well as deep research of the demand of the market. Therefore, there exist issues of constructing centers and basements of cloud computing blindly, to some extent, which leads to planning and starting new items blindly.

(2) Repeating construction. Judging from many regions and construction of cloud computing, there exist issues of repeating construction. National Development and Reform Commission and National Ministry of Industry and Information Technology jointly issue Notice of Doing the Good Job of Innovative Demonstration Pilot about Cloud Computing Service. The notice regards 5 cities, including Beijing, Shanghai, Shenzhen, Hangzhou, and Wuxi as demonstration pilot cities of developing cloud computing ahead of time. At present, Beijing has made and launched "Plan of Auspicious Clouds"; Shanghai also made and launched "Plan of Clouds". But in practice, cloud computing basements are also begun to build in other developed zones except the above 5 cities. Nowadays, as Zhao Bo, Vice Director-General of Electronic Ministry points out that it's very common for some places to construct cloud computing centers repeatedly [14].

(3) Valuing hardware and despising software. There exist the issues of valuing hardware construction and despising software investment, especially disregarding the service. In the area of regional distribution, industry links, software matching, etc., scientific plans and effective controls are lacked, which causes the development of disorder.

(4) Developing in confusion. In the area of regional distribution, industry links, matching of software and hardware, etc., scientific plans and effective controls are lacked.

The causes of the issues are "three lacks". (1) Lacking full demonstration. The effect of cloud computing construction is highly expected. Our country is much more optimistic, and wants to seize the opportunity to strive to be the first, but it lacks enough investigation researches and evaluation. (2) Lacking risk awareness. Nowadays, the development of cloud computing is in the process of discovery. Its technical route, standard specification, resultant specification, resultant mechanism and commercial mode all need trial, and its uncertain factors are obvious. In the reality, people attach less importance to the degree of cloud computing security, and lack the knowledge and awareness of technology, environment, market, financing, benefit, mechanism and other risks of cloud computing. (3) Lacking coordination and cooperation. Each region designs and plans by themselves, and they lack the capability of reasonable layout, coordination and distribution of responsibilities, as well as coordination and cooperation among regions.

Some relevant experts point out that in the relevant industry area of cloud computing, there exists the issue of regional excessive convergence to varying degrees. For instance, the development of our country's software also needs strengthen regional overall plans ${ }^{[15]}$. Scientific and reasonable choice, cultivation as well as development of cloud computing benefit economic development of each region and country, however, excessive convergence and repeating construction will cause vicious competition and the waste of resources. Therefore, the construction and development of cloud computing need coordination and cooperation as well as reasonable layout. In this regard, M\&A integration of cloud computing is a good route choice. 


\section{M\&A Integration and Characteristic Analysis of Cloud Computing in our Country}

M\&A integration of regional cloud computing cultivation means correcting projects because of overbuilding and repeating construction. M\&A integration not only corrects excessive convergence of industrial choice and cultivation, but also boosts industrial assets integration and resources optimization in the long run and overall situation. For some strategic new industries, areas as well as regions, all of which are overbuilt and constructed repeatedly, integration is a good direction of choice.

(1) The general analysis of M\&A integration. In the cultivation process of cloud computing, our country not only need boost industrial technology progress and reform, but also innovate the mode of commerce or management. Such kind of innovation is sure to cause enterprise reshuffle in the industry, and boost horizontal business integration or vertical integration among regional enterprises. As a matter of fact, the tendency of M\&A in the industrial cultivation of cloud computing is begun to appear gradually. According to the statistics of CCID Consulting from 2010 to 2011, cloud computing industry in our country has revealed 127 merger regulations, including 89 merger amount cases that have been revealed, involving merger amount of 15.788 billion yuan. See Figure 1[16].

(2) The regional distribution of M\&A integration. Judging from the distribution of regions, from 2010 to 2011, M\&A cases of cloud computing enterprises included 23 cross border cases and 105 inside border cases. From 2010 to Dec. 2012, among M\&A cases of cloud computing enterprises that have revealed amount, the merger amount of Beijing, Shanghai and Guangdong reached 8.643 billion yuan, accounting for $62.3 \%$ of the total merger amount. The most prominent region was Sichuan Province which had few merger numbers but quite a large merger amount, for Huawei Corporation invested 0.53 billion dollars to purchase $49 \%$ of Symantec Corporation's shares. Consequently, merger amount of Sichuan Province reached 24.9\% of the total amount, becoming the M\&A region after Shanghai. The scale of M\&A in Shanghai was far more than its number of M\&A, which was mainly influenced by the M\&A case that East China Computer purchased ECCOM with 1.803 billion yuan. See Figure 2 [16].

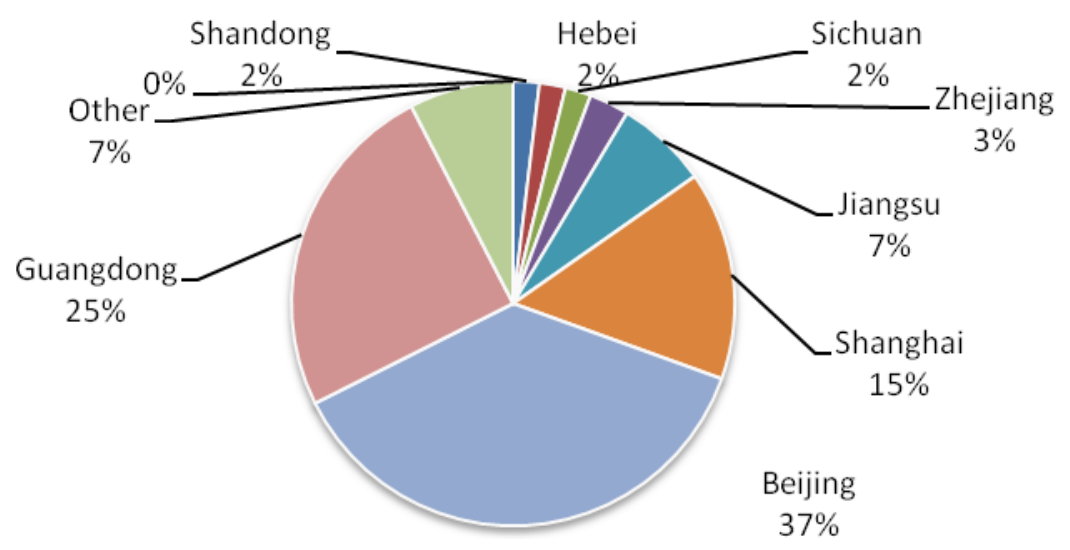

Figure 1. Regional Distribution of Mergers and Acquisitions on Chinese Cloud Enterprise 


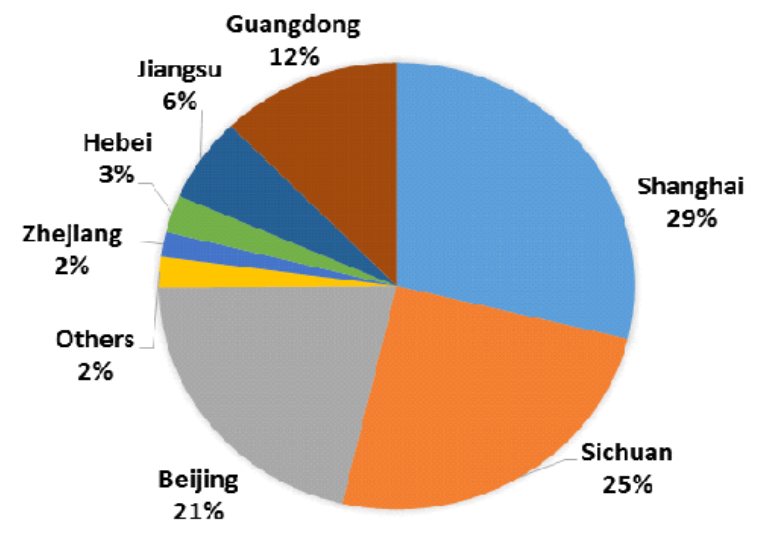

Figure 2. Chinese Cloud-Scale Mergers and Acquisitions

(3) The main characteristics of M\&A. There are 3 obvious characteristics: (i) Complete the extension of technology through capital operation. Three kinds of enterprises become the hot point of M\&A: The enterprise of cloud computing integration and application service with business-specific; the enterprise of unique technology and R\&D capability; the outsourcing partner of customers' IT systems. (ii) Cloud computing which is based on Internet application strengthens integration development continuously, and mobile cloud service and cross-M\&A will be normal. (iii) The competition of industry application and outsourcing service is intensified.

The application and M\&A of cloud computing in our country will increase continuously. Although M\&A integration and recombination of regional cloud computing in our country start soon, there exist some risks. However, its routine is quite a good choice and appears a good tendency. Only when we seek advantage and avoid risk in the industrial cultivation development, and don't have any critical mistakes of decision and operation, will the prospect appear, which benefits the healthy cultivation development of cloud computing.

\section{The Practical Operation of M\&A Integration of Regional Cloud Computing in our Country}

(1) The source, benefit and risk of M\&A integration. M\&A integration of cloud computing industry is based on three points: (i) The demand of cultivating correction. In the industry cultivation, we need correct and solve the issues, deviations and mistakes which happen in the industry choice and cultivation.

Aiming at excessive convergence of regional industry choice and repeating construction of cultivation, we may solve the issues through industrial M\&A integration and recombination which is a better way in the correction mode. (ii) The necessity of industrial upgrading and updating. In the process of industrial upgrading and updating, the industrial cultivation and development need relative concentration, for strategic new industries have higher capital investments, technical contents and added values. Industrial integration is an important way and platform for industrial concentration. (iii) The regulation and guidance of industrial M\&A integration and recombination. 


\begin{tabular}{|c|c|c|c|}
\hline $\begin{array}{l}\text { Comb business } \\
\text { process of } \\
\text { needing } \\
\text { reproduction }\end{array}$ & $\begin{array}{l}\text { Diagnosis of } \\
\text { business } \\
\text { processes }\end{array}$ & $\begin{array}{l}\text { Business process } \\
\text { redesign }\end{array}$ & $\begin{array}{l}\text { Running test and } \\
\text { evaluation of new } \\
\text { s business process }\end{array}$ \\
\hline $\begin{array}{l}\text { Select } \\
\text { reproducing } \\
\text { business } \\
\text { process. }\end{array}$ & $\begin{array}{l}\text { Find out } \\
\text { problems and } \\
\text { reasons of } \\
\text { business } \\
\text { process. } \\
\end{array}$ & $\begin{array}{l}\text { Put forward } \\
\text { reasons of } \\
\text { process } \\
\text { changing. }\end{array}$ & $\begin{array}{l}\text { Operation steps of new } \\
\text { business process: }\end{array}$ \\
\hline $\begin{array}{l}\text { Choose } \\
\text { strategic } \\
\text { process as a } \\
\text { breakthrough } \\
\text { according to } \\
\text { multiple } \\
\text { principles. }\end{array}$ & $\begin{array}{l}\text { Engage experts } \\
\text { to conduct the } \\
\text { efficiency of } \\
\text { process and } \\
\text { performance } \\
\text { evaluation and } \\
\text { judge its crux }\end{array}$ & $\begin{array}{l}\text { Make sure the } \\
\text { process plan. }\end{array}$ & $\begin{array}{l}\text { Pilot projects, patching } \\
\text { programs, widely } \\
\text { communication, } \\
\text { readjusting organization } \\
\text { structure, operating and } \\
\text { optimizing new process. }\end{array}$ \\
\hline $\begin{array}{l}\text { Analyze the } \\
\text { current } \\
\text { situation of } \\
\text { the business } \\
\text { process. } \\
\text { Sketch the } \\
\text { flow charts } \\
\text { and find out } \\
\text { main issues } \\
\text { and its } \\
\text { specific } \\
\text { aspects. }\end{array}$ & $\begin{array}{lr}\text { Make } & \text { sure } \\
\text { redundant } & \\
\text { process, } & \text { issue } \\
\text { process } & \text { and } \\
\text { reasons. } & \end{array}$ & $\begin{array}{l}\begin{array}{l}\text { Draw up a new } \\
\text { plan } \\
\text { compulsory } \\
\text { process. }\end{array} \\
\text { Operate the } \\
\text { outsourcing of } \\
\text { business process } \\
\text { appropriately. }\end{array}$ & \\
\hline
\end{tabular}

Figure 3. Business Process Reengineering Step

In the field of industrial capital recombination and integration, M\&A is one of the most important forms. It's beneficial for profits generated by reasonable layout of the industry, economies of scale acquired by the enterprise, the smooth financial channels, investment profits, the avoidance of enterprise risks, and enhancing industrial competition, for unscientific decisions and unsuitable operations will cause risk of decision-making in M\&A ( motivation differences and risk of overconfidence), risk of operation (asymmetry of information and risk of finance), risk of M\&A ( operation management, economies of scale and risk of enterprise culture).

In the period of M\&A, the enterprise should integrate the new entity effectively in the aspect of business process, human resource, enterprise culture, organization, finance and product etc. in order to make itself play synergy effects really.

(2) The key points of integration in business process [4] and reproduction of enterprise's business process. See operation steps of Figure 3.

(3) Organize the structure and integrate key points [4].

Organize the integration of the enterprise after M\&A. See Figure 4. 


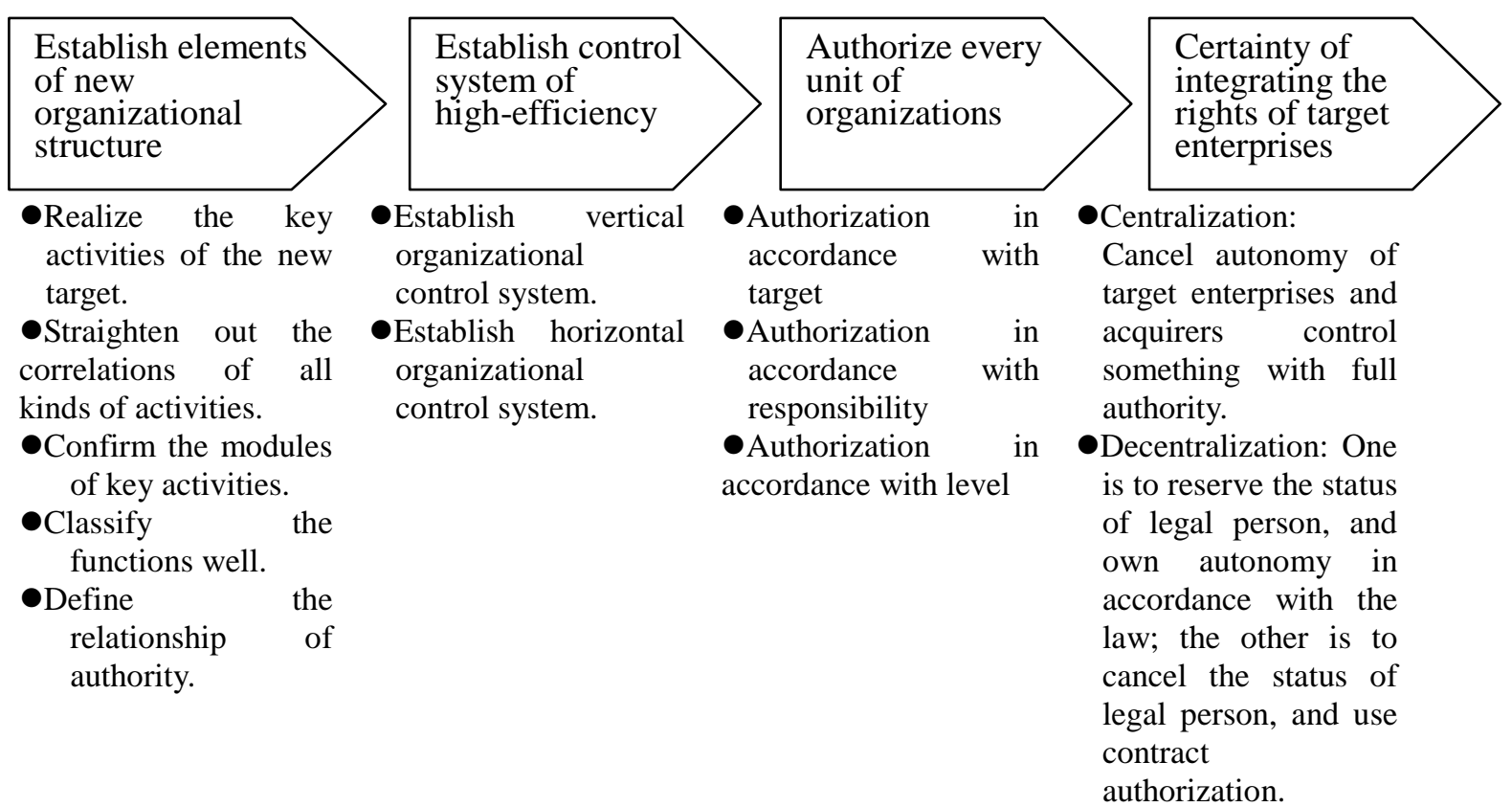

Figure 4. Operation Points about Industry Mergers and Acquisitions Organizational Integration

\section{Measure Excessive Convergence of Mathematical Models in the Area of Regional Cloud Computing}

We may learn mathematical models that respond the convergence level of regional industry ${ }^{[17]}$ to establish mathematical models that measure whether regional cloud computing is in a state of excessive convergence. There are two kinds of methods in detail.

(1) Correlation Coefficient. The formula is as follows:

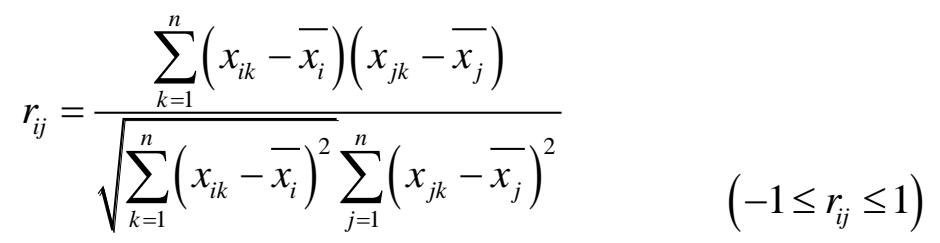

Formula: $r_{i j}$-Correlation coefficient of region $i$ and region $j ; x_{i k}, x_{j k}-$ The proportion of cloud computing $k$ in industrial structure of region $i$ and region $j ; \overline{x_{i}}, \overline{x_{j}}$-The average of industrial structure of every department in region $i$ and region $j$.

When $r_{i j}=-1$, the industrial structure of region $i$ and region $j$ is opposite totally; When $r_{i j}=1$, the relevant industrial structure of cloud computing is the same totally in region $i$ and region $j$; When $r_{i j}$ is closer to 1 , the convergence level of the relevant industrial structure in regional cloud computing is higher; When $r_{i j}>1$, namely excessive convergence.

(2) Similarity coefficient is the method which is advised by UNIDO. The formula is as follows: 


$$
s_{i j}=\frac{\sum_{k=1}^{n} x_{i k} x_{j k}}{\sqrt{\sum_{k=1}^{n} x^{2}{ }_{i k} \sum_{k=1}^{n} x_{j k}^{2}}} \quad\left(0 \leq s_{i j} \leq 1\right.
$$

Formula: $x_{i k}, X_{j k}-$ The proportion of cloud computing $k$ in industrial structure of region $i$ and region $j$; $S_{i j}-$ Similarity coefficient of relevant industrial structure of cloud computing in region $i$ and region $j$.

The value of $S_{i j}$ is from 0 to 1 . The coefficient is bigger, relevant industrial structure of cloud computing in both regions is much simpler. When $S_{i j}=0$, relevant industrial structure of cloud computing in both regions is different totally; When $S_{i j}=1$, industrial structure in both regions is the same totally; When $S_{i j}>1$, namely excessive convergence.

Because cloud computing is an area of new industry, and it lacks relevant statistical data, it cannot be conducted with positive analysis.

\section{The Countermeasures and Safeguards of Regional Cloud Computing Integration in our Country}

In terms of M\&A integration of regional cloud computing in our country, four relations should be dealt with well: (1) The market is decided by the guidance of the government. (2) The relation between economic integration and technological integration (3) The relation between external integration and internal reform (4) The relation between industrial integration and industrial cooperation

As for the safeguards of cloud computing industrial integration, the following issues are of greatest importance.

(1) Strengthen strategic research and top-level design, and do well in reasonable layout of the country and region. We should strengthen strategic research and make reasonable layout. According to the current situation and tendency of cloud computing from home and abroad development, and considering the situation of development as well as the demand of application, we are supposed to quicken the pace of researching and making the strategic and work plan of regional cloud computing in our country, and strengthen publicity guide, overall planning and reasonable layout. Meanwhile, we should avoid blindly following suit and repeating construction in order to boost the healthy and rational development of cloud computing ${ }^{[18]}$. Relevant departments of our country and provinces should work together to develop the work in this area.

(2) Strengthen coordination and cooperation, and do well in the plan and integration of website groups. Considering the coordination of the aspect of systematic management, we should plan websites and integrate website groups. Meanwhile, we should have an overall plan of website groups, including the overall constructive targets, projects and measures, comments and supervision mechanism, etc. [19]. The plan need consider coordination, hierarchy and interactivity of the whole construction of website groups' resources. At the same time, it also emphasizes science, rationality and practicability of the layout. Besides, it also considers reasonable adjustment of current resource allocation, and plan construction of new increased and mobile resources. Finally, the plan tries to realize effective integration of heterogeneous database. For now, website groups should make the development plan themselves actively, launch the upgrades of the construction of cloud technology, and develop 
the resource integration and application of widely e-government information based on the overall plan, interaction and sharing.

(3) Strengthen cloud computing cooperation, and establish shared platform of network resource. To establish exchange platform of shared information. The platform can support data adapter, data transformation, data transmission, statistical analysis, backup management, etc.

To establish shared platform of public service resource. The platform can classify and manage service resource, and offer relevant service link addresses and interfaces of Web Service and other information so that other sites of website groups can be shared and used, and much more convenient service can be offered for the public.

To establish shared platform of infrastructure resource. The platform can manage the infrastructure resource and offer the interface uniformly so that all kinds of sites of website groups can be shared and used.

(4) Develop the demonstration of application pilot, and drive the cultivation and development of application industry. Develop the work of demonstration pilot in cloud computing actively and choose to develop the application pilot of cloud computing in a place and an area that have relative mature conditions. We should conclude and extract experience, perfect key technology, explore commercial mode, enhance the confidence of users, and drive the development of application by way of demonstration projects ${ }^{[20]}$. Our country will regard the demonstration pilots of 5 cities as targets, strengthen the guidance of demonstration of cloud computing in 5 cities, and conclude and extract key technology and commercial mode of cloud computing.

(5) Quicken standardization of cloud computing and improve healthy development of the industry. In accordance with the government's push and giving priority to the enterprise, producing, learning, scientific research and application, we should develop cloud computing application actively, make the work of service standard, establish standard system of cloud computing, participate in international activities of standardization actively, improve standards of making cloud computing area in our country continuously. On one hand, we ought to research and organize the system of standardization; on the other hand, based on SC38 and SC7, we should take an active part in promoting relevant work of international standardization of cloud computing. Meanwhile, in the foundation of promoting national standard, we can make our own contribution to international standard.

(6) Develop leading enterprises and build industrial chains. We encourage large powerful enterprises to concentrate resources, improve innovation and competitiveness, form a group of cloud computing enterprises with strong strength, play a full assistant role, form a good industrial ecological environment, and drive the development of cloud computing.

(7) Cultivate the demand of market and boost good development of industry. An important task of the cultivation of regional cloud computing industry is to strengthen market cultivation. New industries and products need corresponding market demand. Without the market of new products, new industries won't be developed ${ }^{[21]}$. Cloud computing industry need demanders of new industries and products. Besides, the industry need cultivate consuming demands and habits of demanders, and offer necessary knowledge and consuming service of new products.

(8) Strengthen industrial regulation and environmental construction and regularize market behavior.We should improve sincerity level and service quality of the enterprise. At the same time, we should combine the characteristics of cloud computing, and learn 
experience of Europe, America and other developed countries in order to perfect industrial environment of cloud computing development in our country ${ }^{[16]}$.

\section{Conclusion}

The area of cloud computing in our country and around the world develops rapidly, however, there exist issues of regional excessive convergence and repeating construction in the development of cloud computing in our country, which need M\&A integration. Judging from the overall plan, reasonable layout and eight aspects, we should strengthen integration countermeasures and safeguards.

\section{References}

[1] Gartner, Forecast: Public cloud services, worldwide and regions, industry sectors, 2010-2015, 2012.

[2] Chinese Engineering Technology Development Strategy Research Institute: 2014 Chinese strategic emerging industry development report [M]. Beijing: Science and Technology Press, 2014:114.

[3] J. Manyika, M. Chui and B. Brown, "Big data: The next frontier for innovation, competition, and productivity", McKinsey Global Institute, (2011) May.

[4] T. Hey, S. Tansley and K. Tolle, "The Fourth paradigm: Data-Intensive Scientific Discovery", Microsoft, (2009).

[5] Waldrop, MM. Data center in a box-A shipping container stuffed with servers could usher in the era of cloud computing [J]. SCIENTIFIC AMERICAN, vol. 297, no. 2, (2007), pp. 74-77.

[6] D. P. Wall, P. Kudtarkar and V. A. Fusaro, "Cloud computing for comparative genomics", BMC Bioinformatics, vol. 11, (2010), pp. 259.

[7] Y. Y. Zhang and L. T. Guan, "Cloud Computing Assisted Instructions in China", Proceedings of the 2010 International Conference on Educational and Information Technology (ICEIT2010), vol. 2, (2010), pp. 438-440.

[8] H. Q. Wang, D. M. Zhao and J. Kong, "Library knowledge sharing based on Cloud computing"”, 2010 2nd International Conference on Software Technology and Engineering (ICSTE2010), vol. 1, (2010), pp. 424-427.

[9] P. L. Zhou and W. F. Mei, "The analysis of GIS software engineering pattern under the cloud computing environment", Proceedings of the 2010 International Conference on Educational and Information Technology (ICEIT2010), vol. 2, (2010), pp. 450-452.

[10] W. Yi and M. B. Blake, "Service-Oriented Computing and Cloud Computing: Challenges and Opportunities", IEEE Internet Computing, vol. 14, no. 6, (2010), pp. 72-77.

[11] J. Y. Wu, L. D. Ping and X. Z. Pan, "Cloud Computing: Concept and Platform", Telecommunications Science, vol. 25, no. 12, (2009), pp. 23-30.

[12] P. Liu, Y. Shi, F. C. M. Lau, C.-L. Wang and S.-L. Li, "Grid Demo Proposal: AntiSpam Grid", IEEE International Conference on Cluster Computing, Hong Kong, selected as one of the excellent Grid research projects for the Grid Demo session, (2003) December 1-4.

[13] L. Baoling, "China software industry: from simple Jingyue to blossom everywhere", Chinese economy, (2011) September 20.

[14] W. Xiaoping, "Cloud computing construction partial heat, the government should plan as a whole", Chinese economy, (2011) September 8.

[15] China Electronic Research Institute, Investment and financing and M \& A strategy Chinese emerging industries of strategic importance, Beijing: Publishing House of electronics industry, (2012).

[16] Y. Jie, T. Haijing and Z. Hongjun, "Cloud computing integration mode based on government websites", E-government, (11), (2010).

[17] F. Jia, "Study on the problem of industrial structure", Beijing: Renmin University of China press, (1997).

[18] M. Porter, "Competitive advantage of Nations", Beijing: Huaxia Publishing House, (2002).

[19] CCID Consulting Service Co. Ltd., "Investment and financing and M \& A strategy Chinese emerging industries of strategic importance", Beijing: Publishing House of electronics industry, (2012).

[20] W. Keqiang, "System and mechanism reform is the key to the development of strategic emerging industries", The science times, (2011) April 20.

[21] Z. Guangqing, "Cloud computing, we have the advantage of backwardness", The science times, (2011) September 20 . 